\title{
Three Protocols Designed to Individualize and Maximize Anti-Cancer Drug Therapy
}

\author{
Arthur J. Weiss, Irwin L. Stoloff* \\ Division of Medical Oncology, Thomas Jefferson University Hospital, Philadelphia, Pa, USA \\ Email: ajw.law160@gmail.com
}

Received 29 October 2015; accepted 27 November 2015; published 30 November 2015

Copyright @ 2015 by authors and Scientific Research Publishing Inc.

This work is licensed under the Creative Commons Attribution International License (CC BY). http://creativecommons.org/licenses/by/4.0/

(c) (i) Open Access

\begin{abstract}
The role that attaining maximum drug dosage intensity plays in many anti-cancer protocols is a major one, particularly in those protocols that attempt to totally eradicate the neoplasm. A classic approach to facilitate this process utilizes stem cell transplants as well as the use of hematopoetic growth factors. However, problems arise with both allogenic and autologous transplants as well as from the significant variability in drug tolerance between individual patients. With average fixed dose protocols, these problems substantially limit the ability to optimize drug dosage. We attempted to circumvent this difficulty by using low dose continuous infusional therapy of variable duration depending upon the patient's response, together with simultaneous hematopoietic growth factor support. This paper presents our results with three drugs, doxorubicin, ifosphamide, and vinorelbine. With these protocols, we were able to individualize and optimize the amount of drug delivered to each patient, as well as to substantially increase the drug dosage intensity of each of these agents.
\end{abstract}

\section{Keywords}

Dosage, Intensification, Doxorubicin, Ifosphamide, Vinorelbine, Schedule, Modification

\section{Introduction}

A major unsolved problem that had plagued medical oncologists since the first anti-cancer agents were introduced was the substantial variation in patient sensitivity to any specific anti-cancer agent. Variation in responses is even known to occur in patients who receive the same course of treatment at different times. One common cause for this is stem cell depletion occurring after several courses of chemotherapy. Other factors are related to genetic factors such as a defect in the dihydropyrimidine dehydrogenase gene in patients receiving 5-fluoroura-

*Deceased.

How to cite this paper: Weiss, A.J. and Stoloff, I.L. (2015) Three Protocols Designed to Individualize and Maximize Anti-Cancer Drug Therapy. Journal of Cancer Therapy, 6, 1103-1113. http://dx.doi.org/10.4236/jct.2015.612120 
cil [1] [2], the SLC19A1 gene complex in patients receiving anti-folates [3], the NADPH quinone oxidoreductase gene complex for many anti-tumor quinines [4], the multiple enzyme complexes involved in the AMPKBcl-2/Bax pathway [5], the PI3K and AKT pathways [6] [7], as well as enzyme complexes related to the ability of cardiac myocytes to neutralize doxorubicin [8]-[10]. Commonly the exact cause or causes of the unexpected adverse reaction to drug remain(s) unknown. For that reason, we devised a general protocol that allowed each patient to determine their own optimal dose.

\section{Materials and Methods}

\subsection{Patient Selection}

\subsubsection{Doxorubicin}

All patients selected had to be non hormonal anti-cancer chemotherapy naive although prior hormonal therapy was acceptable. Normal renal, cardiac, and hematopoietic functions were required. Because of the use of hematopoietic growth stimulants hematologic malignancies were excluded from this study.

\subsubsection{Ifosphamide}

Only 12 patients that were chemotherapy-naïve were available for this study. Therefore it was expanded to include patients that have had limited exposure to doxorubicin. All patients were required to have a normal creatinine clearance. The other requirements were similar to those stated for doxorubicin.

\subsubsection{Vinorelbine}

As with doxorubicin, also including a requirement, there was no evidence of significant neurologic disease.

\subsection{Regimes}

\subsubsection{Doxorubicin}

Protocol: Patients were started on Gm-Gsf $250 \mathrm{mcgm} . / \mathrm{M}^{2}$ sc. daily. Forty-eight hours later they were started on doxorubicin, $8 \mathrm{mgm} . / \mathrm{M}^{2}$, given by infusion over 24 hours, daily. Their W.B.C. rapidly increased achieving a level of $10,000 / \mathrm{mm}^{3}$ or more. Regardless of the amount of doxorubicin delivered, the infusion was continued as long as the W.B.C. was over $9000 / \mathrm{mm}^{3}$. Once a rapid fall in W.B.C. occurred, the drug infusion was stopped but the Gm-Csf continued. Following stoppage of doxorubicin, the W.B.C. almost always fell to a level of between $800 / \mathrm{mm}^{3}$ and $2500 / \mathrm{mm}^{3}$ while the platelet count usually fell to a level of between $10,000 / \mathrm{mm}^{3}$ and $60,000 / \mathrm{mm}^{3}$. The pancytopenia and thrombocytopenia usually lasted between three and eleven days and was followed by a rapid rise in the white blood cell and platelet count. Once this occurred the doxorubicin infusion was restarted at the same dose and continued until the W.B.C. again fell. The number of courses varied depending upon the patient's response to therapy and the specific protocol that the patient was enrolled in.

\subsubsection{Ifosphamide}

Gm-Csf, same dose and schedule as with doxorubicin. Dose of ifosphamide $2.0 \mathrm{gm} . / \mathrm{M}^{2} /$ day is given over 6 hours each day. Mesna was given at a daily dose of $20 \%$ of ifosphamide dose. A Serum B.U.N. and creatinine was obtained q 2nd day. The infusion was stopped if a significant increase in either occurred. Remainder of the protocol followed the doxorubicin protocol. Because most patients showed significant decreases in creatinine clearance following the first course only 3 patients received 2 consecutive courses and none received 3 . Four patients were studied, in all the creatinine clearance required 6 to 8 weeks to return to its baseline values.

\subsubsection{Vinorelbine}

Gm-Csf same dose and schedule as doxorubicin. Dose of vinorelbine $6.0 \mathrm{mgm} . / \mathrm{M}^{2} /$ day is given each day over 24 hours. Remainder of the protocol followed the doxorubicin protocol. There was a provision in the vinorelbine regime allowing for cessation of therapy if substantial neurotoxicity was noted, however this very rarely happened.

\section{Results and Discussion}

The concept of dosage intensification has been a major factor in the design of anti-cancer drug regimes since the initiation of modern anti-cancer chemotherapy, particularly when the goal is total eradication of residual tumor. 
This is primarily due to the fact that the dose response curve against essentially all tumors is very steep and thus the amount of drug required to totally eliminate the tumor may be much greater than that required to eliminate the bulk of the tumor [11] [12]. It has also been postulated that there is a separate population of stem cells in many neoplasms that are intrinsically resistant to standard doses of chemotherapy and that continuously repopulates the neoplasm [13]-[15].

The importance of dosage intensification has been demonstrated to be true for alkylating agents [16]-[18], anti-neoplastic antibiotics, such as the taxanes and anthracycline derivatives [18]-[21], nucleic acid antagonists [19]-[25] anti-tumor antibodies [25] and platinum compounds [26] [27]. It has shown to apply to many malignancies such as some sarcomas [16] [17], most but not all hematologic malignancies [19] [22] [24] [25] [28], as well as germ cell neoplasms, [29]-[31]. However, among others, the value of dosage intensification for some sarcomas [21], carcinoma of the breast [32]-[34], lung [35] [36] and a subset of lymphoblastic leukemia [28], has been questioned.

Many difficulties occur when it is attempted to define a standard, fixed dose protocol that results in the majority of patients receiving an optimal dose. A major reason for this is that some individuals show marked differences in their sensitivity to a specific cancer agent, therefore, for safety purposes, the total dose selected for the specific trial is commonly below an optimum dose for a significant number of patients.

Two cases in our practice illustrate this problem. A 67-year-old man was found that have a carcinoma of the ascending colon with hepatic metastatic disease. He received a single dose of $500 \mathrm{mgm}$. of 5-fluorouracil. Within 36 hours he had severe diarrhea, within 48 hours a marked pancytopenia was noted. Extreme diarrhea and stomatitis followed. He developed a severe pancytopenia which persisted for 36 days, diarrhea persisted for 25 days. He received no further chemotherapy. Surprisingly all evidence of hepatic metastatic disease disappeared and he remain free of tumor until his death from an acute myocardial infarction occurred approximately three years later. We could not determine whether this patient had a deficiency in dihydropyrimidine dehydrogenase.

A young man arrived at our clinic with a Ewings tumor of his thigh. Extensive workup including an aspiration bone marrow biopsy was normal as was the family history for hematologic disease. Following surgical excision of the mass, he received a single injection of doxorubicin, $20 \mathrm{mgm} . / \mathrm{M}^{2}$. He developed a profound marrow aplasia, his WBC falling to under $100 / \mathrm{mm}^{3}$, platelets less than $10,000 / \mathrm{mm}^{3}$. Hematopoietic recovery was slow, taking 70 days to complete; however since then his hematologic parameters have remained normal and the patient remains free of tumor to this date. On the other hand, during our initial phase one doxorubicin studies, two patients received $120 \mathrm{mgm} . / \mathrm{m}^{2}$ of doxorubicin by bolus. Both patients had only moderate stomatitis and transient hematologic suppression. When we inspected our preliminary results in 1980 it was apparent that any standard dose of doxorubicin resulted in a rather large range of marrow suppression and an ideal dose for each patient, provided your aim was maximal dosage intensification, was not possible using a standard dosing schedule.

Current dogma states that the simultaneous use of G-Csf or GM-Csf with anticancer chemotherapeutic agents, in general, is contraindicated. This is due to the finding that the simultaneous use of G-Csf with a standard schedule of 5-fluorouracil and topotecan resulted in a marked increase in the toxicity of each drug [37]-[39]. As the data in this paper demonstrates, and as other publications show, this is not true for doxorubicin [40]-[44], an anthracycline, ifosphamide [40] [41], an alkylating agent, and vinorelbine [45], a vinca alkaloid. With these 3 agents, the simultaneous administration of Gm-Csf decreased the level of toxicity for a specific dose thereby allowing the total dose per course to be substantially increased. For these reasons, recent recommendations concerning the simultaneous use of cytokines and anti-cancer chemotherapy have, to a limited degree, been modified [46].

There is no question that the use of G-Csf increases in the toxicity of 5-fluorouracil and topotecan. However the following question has not been addressed. If the dose of 5-fluorouracil or topotecan is adjusted downward so that the ensuing toxicity is tolerable, is the anti-tumor effect superior, equal or inferior to that seen when the drugs and hematopoietic cytokines are use in a conventional manner? When G-Csf was first introduced our group treated 3 patients with metastatic colon carcinoma with a standard dose of 5-Fluorouracil and G-Csf, the latter given on days 1, 2, and 3. All developed severe and prolonged hematologic and gastrointestinal toxicity that eventually reversed itself. One of the patients had a carcinoma of the ascending colon with regional nodal involvement and multiple masses in the liver, believed to be due to metastatic disease. All evidence of metastatic disease disappeared and he remained free of disease for 8 months before his metastatic disease recurred. The second patient, again with a carcinoma of the colon with extensive regional nodal disease, but no evidence of 
distant metastatic disease, following surgery had a single standard course of 5-fluorouracil again with G-Csf administered on day 1, 2, and 3 . He developed a similar pattern of toxicity which required 56 days to resolve. He remained clinically free of malignant disease for the remaining 5 years of his life. The third patient again had metastatic disease involving his liver. He showed only a minimal and transient regression of his tumor which led to his demise shortly thereafter. His pattern of toxicity was similar to the first two patients discussed. Thus the question is not whether the combination of the cytokine and chemotherapy increases the toxicity of a specific anti-cancer agent, but whether it affects the ratio of tolerable toxicity to anti-tumor effect when the dose of the chemotherapy is adjusted to a tolerable level of toxicity. As far as I know, this question has not been answered with any anti-cancer agent that I am familiar with.

Essentially all the patients in these studies received other anti-cancer agents following completion of each of the protocols, thus determining remission rates for each was not possible; however initial response rates were very high, especially in sarcomas, breast cancer, and germ cell tumors. Thus in those patients in each of the groups that had clearly defined pulmonary metastatic lesions over $70 \%$ show a decrease in the major diameter of the metastatic lesions of $30 \%$ or more. With $25 \%$ of these patients with germ cell neoplasms and $18 \%$ of these patients with breast carcinoma complete disappearance of all measurable lesions occurred following 2 courses of doxorubicin.

In regard to the protocols presented in this paper, typical hematologic response curves for doxorubicin, ifosphamide and vinorelbine are shown in Figures 1-3. And tolerated doses and duration of each of the courses is presented in Tables 1-3.

The amount of each drug delivered by accepted standard regimes, a typical dose dense regime, and the 3 infusion regimes is charted in Tables 1-3.

It is apparent from these tables that there is a substantial variation in the amount of each the 3 drugs studied in regard to the amount required to induce a similar drug limiting hematologic toxicity. Thus, in the doxorubicin group, the patient most tolerant of the drug received 2.2 times as much as the most sensitive individual to reach the same level of hematologic toxicity. The doxorubicin data presented here also suggests that there are two groups of patients in regard to resistance to doxorubicin toxicity, with one group able to tolerate much higher total doses than the other group. Whether this is due to an increased ability to degrade the drug, an increased capacity of the hematopoietic system to resist the drug, or both, is unclear. It is also possible that the results are due to the small numbers of patients in each group and are only statistical artifacts. Similar differences in doses required to result in the same level of hematologic toxicity were found with the 2 other drugs studied.

Essentially all patients in the doxorubicin studies received further therapy with doxorubicin. Despite the very

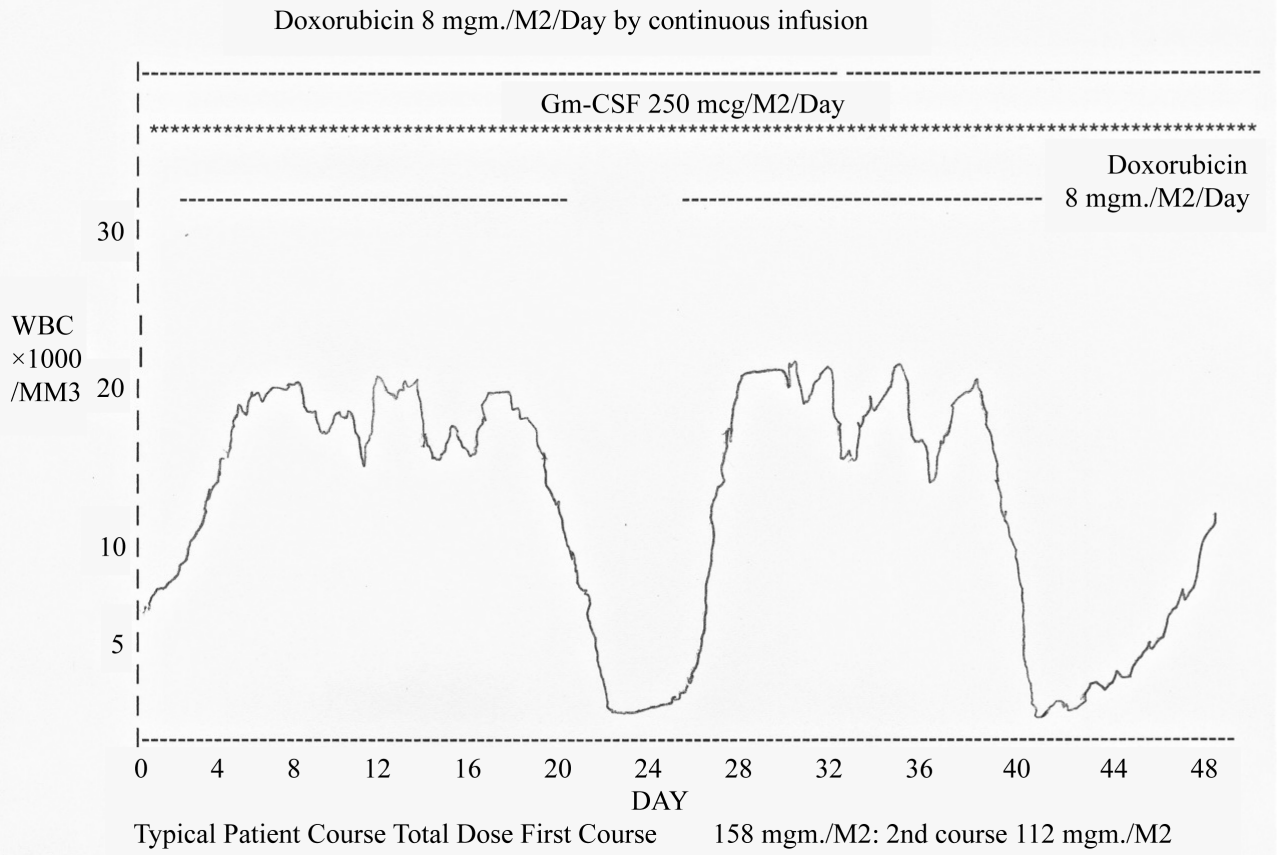

Figure 1. Hematologic response to infusional doxorubicin. 


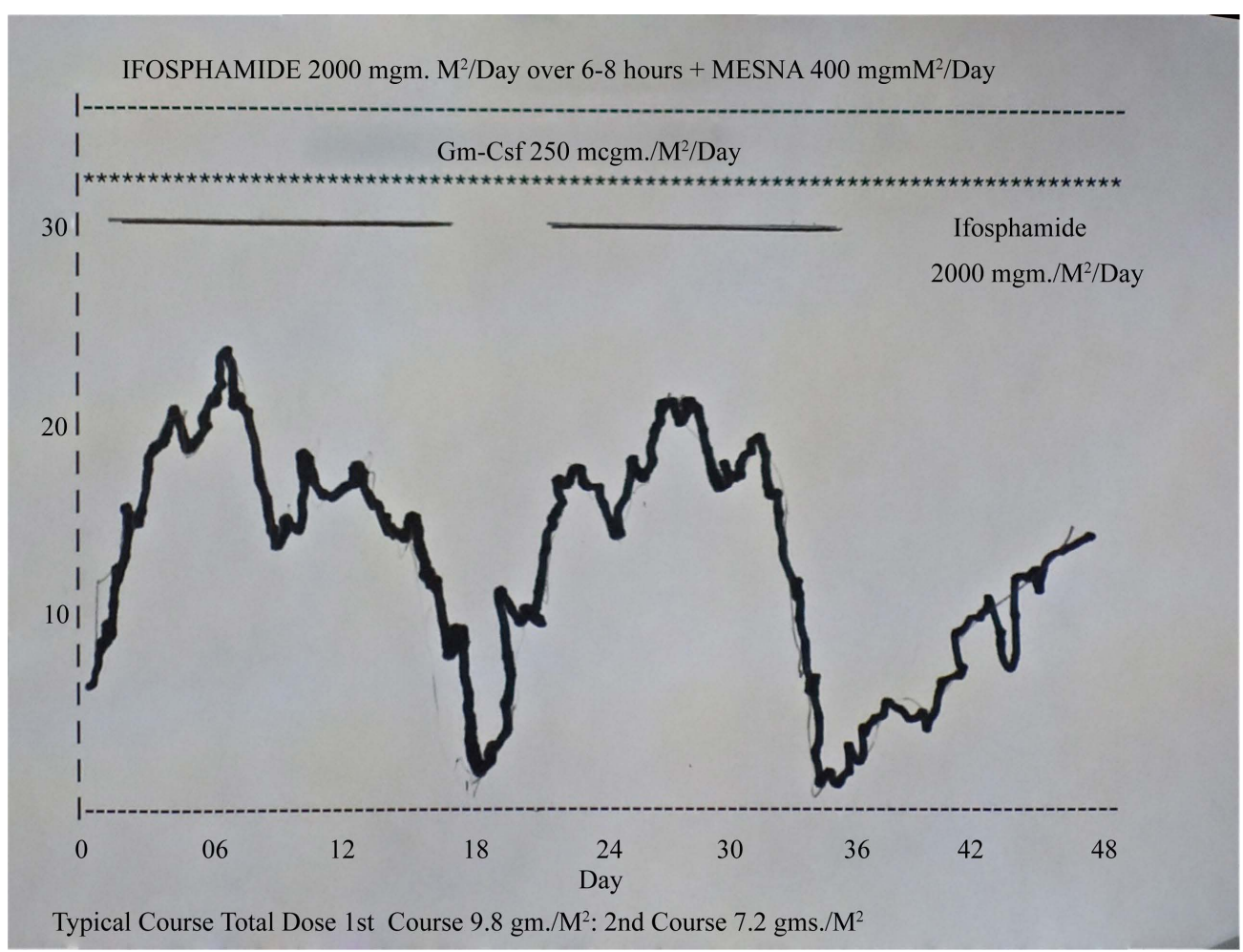

Figure 2. Hematologic response to infusional ifosphamide.

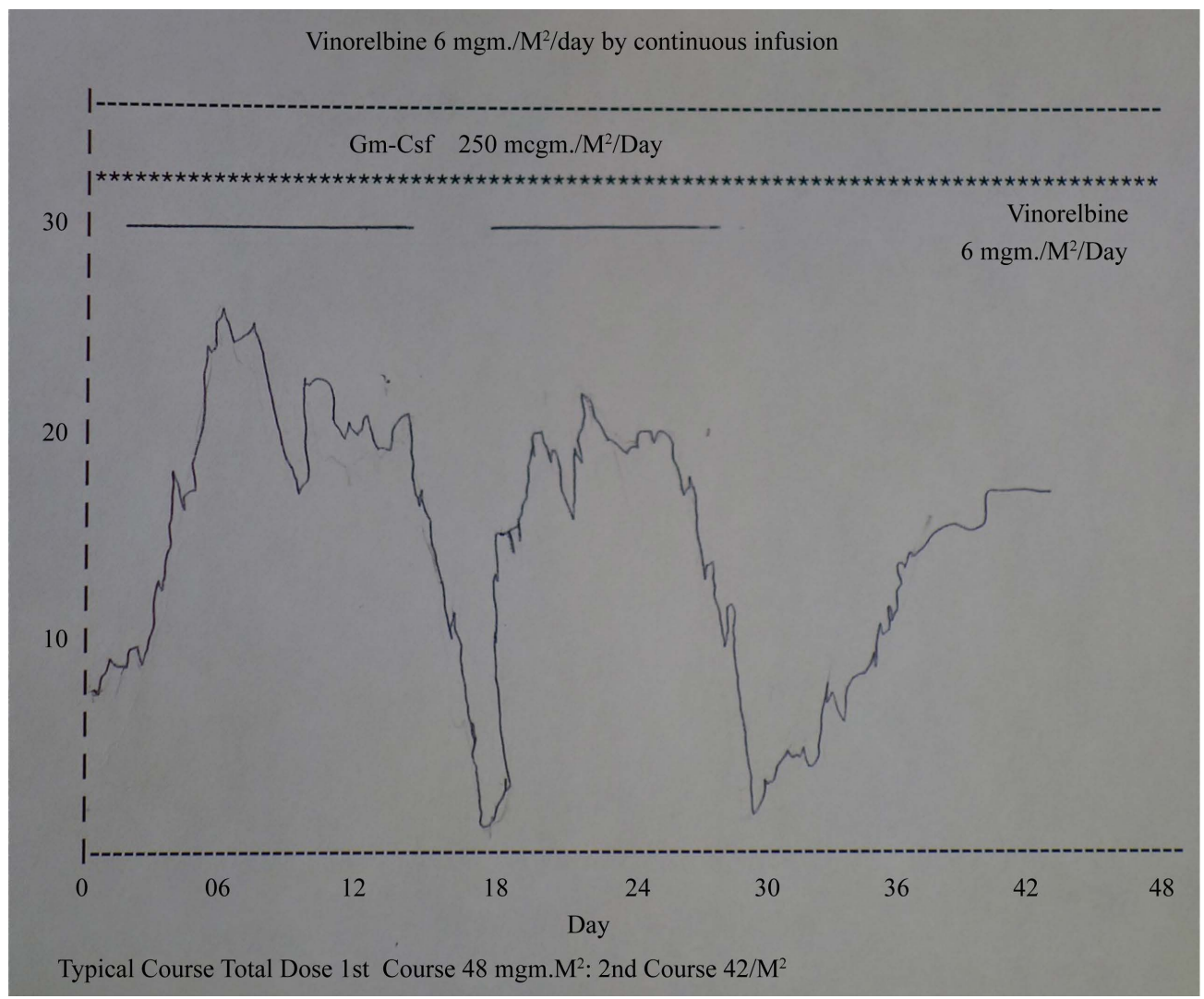

Figure 3. Hematologic Response to Infusional Vinorelbine. 
Table 1. Doxorubicin containing course.

\begin{tabular}{|c|c|c|c|c|c|c|c|c|}
\hline Regime & Details & $\begin{array}{l}\text { Total dose* } \\
\text { initial period } \\
\text { \& its length }\end{array}$ & $\begin{array}{c}\text { Average } \\
\text { dose* } \\
\text { q day initial } \\
\text { period }\end{array}$ & $\begin{array}{c}\text { Total dose* } \\
\text { complete } \\
\text { Regime }\end{array}$ & $\begin{array}{l}\text { Av. daily* } \\
\text { dose } \\
\text { Total } \\
\text { Regime }\end{array}$ & $\begin{array}{c}\text { Total length } \\
3 \text { infusions } \\
\text { minimum }\end{array}$ & $\begin{array}{l}\text { Total length } \\
3 \text { infusions } \\
\text { maximum }\end{array}$ & $\begin{array}{l}\text { Peak } \\
\text { dose } \\
\text { level }\end{array}$ \\
\hline Standard & 60 to $75^{* \wedge}$ & $70 *$ & 3.57 & 3 courses & 3.56 & & & 70 \\
\hline Regime* [11] & q 21 days & q/21 days & & 210*@ & & & & \\
\hline Hudis High Dose*^ [39] & 90q 14 days x3 & 270/q 42 days & 6.43 & 270 & 2.14 & & & 90 \\
\hline regime 42 patients & total course & & initial 42 & & total 125 & & & \\
\hline G-Csf before and after dox & 126 days & & day period & & day period & & & \\
\hline dox 8 mgm/M²/day infusion & 24 hour daily & & & & & & & \\
\hline until toxicity & infusion with & & & & & & & \\
\hline [low dose group 23 patients] & 250 mcmg. & $80-99$ & 4.22 & 236 & 4.24 & 44.0 days & 51.0 days & 9.6 \\
\hline [mid dose group 10 patients] & Gm-Csf q day & $101-124$ & 6.67 & 301 & 5.16 & 53.0 days & 61.0 days & 9.7 \\
\hline [high dose group 34 patients] & sub cut. & $125-188$ & 7.66 & 357 & 5.95 & 56.0 days & 85.0 days & 9.7 \\
\hline entire group 67 patients & each group & 132.04 & 7.08 & 322 & 5.22 & 58.4 days & 66.1 days & 9.7 \\
\hline
\end{tabular}

*per mgm./M²; with G-Csf administered before and after Dox.; followed by multiple non anthracycline anti-cancer agents; ^given by bolus; \#given simultaneously with sub. cut. 250 mcng Gm-Csf q day.

Table 2. Ifosphamide containing courses.

\begin{tabular}{cccc}
\hline Regime & Details of regime* & $\begin{array}{c}\text { Total dose per initial period } \\
\text { and its length }\end{array}$ & $\begin{array}{c}\text { Av. dose/day initial } \\
\text { period } 21 \text { days }\end{array}$ \\
\hline Standard Regime* & 6 gms/M² q 21 to 28 days & ave 6 q 21 days & 3.57 \\
with mesna dose $20 \%$ & & \\
Ifosphamide dose & 6 - 8 hour infusion q day & low $8 *$ in 4 days & 4.22 \\
\hline Infusion regime & with mesna $20 \%$ ifos dose & high $14^{*}$ in 7 days & 7.02 \\
Ifo. $2 * /$ day & and Gm-Csf 250 mcmg/day & Av. $11.5 *$ in 5.8 days & 6.65 \\
\hline
\end{tabular}

*gms./day given by 6 - 8 hour infusion q day; \#given simultaneously with Gm-Csf.

Table 3. Vinrelbine containing courses.

\begin{tabular}{|c|c|c|c|c|c|}
\hline Regime & $\begin{array}{l}\text { Initial course } \\
\& \text { its length* }\end{array}$ & $\begin{array}{c}\text { Av. daily dose* } \\
\text { Initial period of } 7 \text { days }\end{array}$ & $\begin{array}{c}\text { Total dose* } \\
3 \text { courses }[27 \text { days }]\end{array}$ & $\begin{array}{l}\text { Average daily dose } \\
3 \text { courses* }\end{array}$ & Peak dose \\
\hline Standard regime & $30 * / q 7$ days by bolus & 4.32 & 90 & 3.33 & 29.8 \\
\hline Infusion & cont inf over 24 hrs daily & & & & \\
\hline low group & 51.16/9.75 days* & 5.21 & 171/33.0 days & 5.19 & 7.9 \\
\hline High group & 84.22/17.91 days* & 5.71 & 218/38.3 days & 5.68 & 7.9 \\
\hline mean both grps. & $64.49 / 11.62 *$ & 5.55 & 199/35.8 days & 5.56 & 7.9 \\
\hline
\end{tabular}

: average; *: all per mgm./M²; \#: given simultaneously with Gm-Csf. 
large amount of doxorubicin received by many of these patients, none developed any evidence of either early or late doxorubicin related cardiac disease [44].

Another factor to consider in these studies is the fact these many of these cytokines have anti-tumor effects as isolated agents and may have a synergistic effect when used in combination with standard chemotherapeutic agents. Gm-csf was originally selected because it is a potent inducer of dendritic cell populations [47]-[55]. The hope was that the destruction of tumor by the chemotherapy would produce a large population of fragments of the tumor that would react as an antigenic stimulus to augment the effect of the anti-tumor agent on the neoplasm. Gm-Csf has been reported to have some activity as an anti-neoplastic agent against melanomas, several carcinomas and sarcomas [47]-[55] and therefore was believed to be a logical agent to use in this fashion, as has rituxan [25] [55] Many biologic agents are now available, many also have the advantage that their primary target is non hematologic.

Possible explanation for the findings that Gm-Csf may protect the bone marrow with these drugs may be found in some studies done by Dr. Cantarow's group at Thomas Jefferson Medical College more than 60 years ago. Castrated male Sprague-Dawley rats were given graded doses of both testosterone and 5-fluorouracil daily. The increase in the dry weight of the seminal vesicles significantly increased as the dose of testosterone increased. If low doses of testosterone were used as a stimulus, 5-fluorouracil prevented any increase in the weight of the seminal vesicles, while if the dose of testosterone was high the increase in weight of the seminal vesicles was very high and totally independent of the dose of 5-fluorouracil, and paralleled that of a group receiving the same dose of testosterone without receiving 5-fluorouracil. Also, the levels of thymidylate synthetase and uridine kinase markedly increased in the seminal vesicles in those animals receiving both 5-fluorouracil and high doses of testosterone. Damage to gut and bone marrow was not affected in any way by any dose of testosterone. When these tissues were assayed for thymidylate synthetase the concentration of this enzyme was very low, decreased or remained very low or decreased further when 5-fluorouracil was given, and the levels of these enzymes were not affected by the administration of testosterone [56]-[58].

While these protocols have several advantages, as described above, they are associated with several problems. They are more expensive, have high manpower commitments, and require more laboratory studies than the average protocol. They require the use of an external pump and continuous anticoagulation. Drug preparation can be complex and errors can lead to fatalities [59]. They also require much more cooperation and decision-making from the patient than the average protocol. Many of our patients were under 50 years of age, a high percentage under 30 and may have a superior marrow reserve; we found that these patients were much easier to work with than the older patient. However, many protocols have been carried out using long term continuous infusion with a low complication rate and interesting results [60].

\section{Conclusions}

We believe that we have demonstrated several points of significance:

1) It is possible to give Gm-csf and G-csf simultaneously with doxorubicin, Ifosphamide and vinorelbine without undue toxicity or adversely affecting the amount of drug given.

2) If the drugs are given by low dose continuous infusion, it is possible both to individualize and maximize the amount of drug that the individual patient receives. This dose is almost always substantially greater than that the patient will have received a standard fixed dose protocol was followed. To attain the same degree of hematologic toxicity, the most tolerant patient received approximately two times as much of each of these drugs as the most sensitive patient. Whether this was due to the fact that the individuals most resistant to the drug had an increased ability to metabolize the drug or a more adequate hematopoietic reserve was not determined by these studies.

3) Because of the limited number of patients in each arm of this study with a specific disease the relative efficiency as far as the anti-tumor affect, compared to other studies, could not be accurately determined. However in all those neoplasms in which a significant number of patients were treated the anti-tumor effect was substantial. The E.C.O.G. partial and complete initial response rates in patients with breast cancer treated with doxorubicin was $72 \%$, that of germ cell tumors treated with doxorubicin was $89 \%$.

4) A study of the simultaneous use of Gm-Csf with infusional doxorubicin in 4 patients resulted in a substantial increase in cd11 and cd123 labelled cells in each indicating a mobilization of dendritic cell types. This suggests that a cellular antibody response might be occurring that could possibly act in synergism with doxorubicin in destroying the tumor. 


\section{References}

[1] Toffoli, G., Giodini, L., Buonadonna, A., Berretta, M., De Paoli, A., Scalone, S., Miolo, G., Mini, E., Nobili, S., Lonardi, S., Pella, N., Lo Re, G., Montico, M., Roncato, R., Dreussi, E., Gagno, S. and Cecchin, E. (2015) Clinical Validity of a DPYD-Based Pharmacogenetic Test to Predict Severe Toxicity to Fluoropyrimidines. International Journal of Cancer, 137, 2971-2980. http://dx.doi.org/10.1002/ijc.29654

[2] Nakamura, M., Yamada, Y., Muro, K., Takahashi, K., Baba, H., Sasaki, Y., Komatsu, Y., Satoh, T., Mishima, H., Watanabe, M., Sakata, Y., Morita, S., Shimada, Y. and Sugihara, K. (2015) The SOFT Trial: A Phase III Study of the Dihydropyrimidine Dehydrogenase Inhibitory Fluoropyrimidine S-1 and Oxaliplatin (SOX) plus Bevacizumab as First-Line Chemotherapy for Metastatic Colorectal Cancer. Future Oncology, 11, 1471-1478.

[3] Yee, S.W., Gong, L., Badagnani, I., Giacomini, K.M., Klein, T.E. and Altman, R.B. (2010) SLC19A1 Pharmacogenomics Summary. Pharmacogenetics and Genomics, 20, 708-715. http://dx.doi.org/10.1097/FPC.0b013e32833eca92

[4] Siegel, D., Chao Y. and Ross, D. (2012) NAD(P)H:Quinone Oxidoreductase 1 (NQO1) in the Sensitivity and Resistance to Antitumor Quinones. Biochemical Pharmacology, 83, 1033-1040.

[5] Gibson, L.F., Fortney, J., Magro, G., Ericson, S.G., Lynch, J.P. and Landreth, K.S. (1999) Regulation of BAX and BCL-2 EXPRESsion in Breast Cancer Cells by Chemotherapy. Breast Cancer Research and Treatment, 55, 107-117. http://dx.doi.org/10.1023/A:1006175811676

[6] Geng, X., Xie, L. and Xing, H. (2015) PI3K Inhibitor Combined With Chemotherapy Can Enhance the Apoptosis of Neuroblastoma Cells in Vitro and in Vivo. Technology in Cancer Research \& Treatment, pii: 1533034615597366.

[7] Arques, O., Chicote, I., Puig, I., Tenbaum, S.P., Argiles, G., Dienstmann, R., Fernandez, N., Caratu, G., Matito, J., Silberschmidt, D., Rodon, J., Landolfi, S., Prat, A., Espin, E., Charco, R., Nuciforo, P., Vivancos, A., Shao, W., Tabernero, J. and Palmer, H.G. (2015) Tankyrase Inhibition Blocks Wnt/ $\beta$-Catenin Pathway and Reverts Resistance to PI3K and AKT Inhibitors in the Treatment of Colorectal Cancer. Clinical Cancer Research, in Press. http://dx.doi.org/10.1158/1078-0432.CCR-14-3081

[8] Hofman, J., Skarka, A., Havrankova, J. and Wsol, V. (2015) Pharmacokinetic Interactions of Breast Cancer Chemotherapeutics with Human Doxorubicin Reductases. Biochemical Pharmacology, 96, 168-178. http://dx.doi.org/10.1016/j.bcp.2015.05.005

[9] Völler, S., Boos, J., Krischke, M., Würthwein, G., Kontny, N.E., Boddy, A.V. and Hempel, G. (2015) Age-Dependent Pharmacokinetics of Doxorubicin in Children with Cancer. Clinical Pharmacokinetics, 54, 1139-1149. http://dx.doi.org/10.1007/s40262-015-0272-4

[10] Datta, A., Bhasin, N., Kim, H., Ranjan, M., Rider, B., Abd Elmageed, Z.Y., Mondal, D., Agrawal, K.C. and Abdel-Mageed, A.B. (2015) Selective Targeting of FAK-Pyk2 axis by Alpha-Naphthoflavone Abrogates Doxorubicin Resistance in Breast Cancer Cells. Cancer Letters, 362, 25-35. http://dx.doi.org/10.1016/j.canlet.2015.03.009

[11] DeVita, V., Lawrence, T. and Rosenberg, S. (2014) Devita, Hellman, and Rosenberg's Cancer: Principles \& Practice of Oncology. 10th Edition, Wolters Kluwer, Philadelphia.

[12] Sweetenham, J.W. (1995) The Importance of Dose and Schedule in Cancer Chemotherapy: Haematological Cancer. Anticancer Drugs, 6, 7-15. http://dx.doi.org/10.1097/00001813-199510005-00002

[13] Lin, K.Y., Ye, H., Han, B.W., Wang, W.T., Wei, P.P., He, B., Li, X.J. and Chen, Y.Q. (2015) Genome-Wide Screen Identified Let-7c/miR-99a/miR-125b Regulating Tumor Progression and Stem-Like Properties in Cholangiocarcinoma. Oncogene, Published Online.

[14] Prindull, G. (2015) Potential Gene Interactions in the Cell Cycles of Gametes, Zygotes, Embryonic Stem Cells and the Development of Cancer. Frontiers in Oncology, 5, 200. http://dx.doi.org/10.3389/fonc.2015.00200

[15] Franqui-Machin, R., Wendlandt, E.B., Janz, S., Zhan, F. and Tricot, G. (2015) Cancer Stem Cells Are the Cause of Drug Resistance in Multiple Myeloma: Fact or Fiction? Oncotarget, Published Online.

[16] Patel, S.R., Vadhan-Raj, S., Papadopolous, N., Plager, C., Burgess, M.A., Hays, C. and Benjamin, R.S. (1997) HighDose Ifosfamide in Bone and Soft Tissue Sarcomas: Results of Phase II and Pilot Studies-Dose-Response and Schedule Dependence. Journal of Clinical Oncology, 15, 2378-2384.

[17] Magnan, H., Goodbody, C.M., Riedel, E., Pratilas, C.A., Wexler, L.H. and Chou, A.J. (2015) Ifosfamide DoseIntensification for Patients with Metastatic Ewing sarcoma. Pediatric Blood \& Cancer, 62, 594-597. http://dx.doi.org/10.1002/pbc.25373

[18] Honkoop, A.H., van der Wall, E., Feller, N., Schuurhuis, G.J., van der Vijgh, W.J., Boven, E., van Groeningen, C.J., Giaccone, G., Hoekman, K., Vermorken, J.B., Wagstaff, J. and Pinedo, H.M. (1997) Multiple Cycles of High-Dose Doxorubicin and Cyclophosphamide with G-CSF Mobilized Peripheral Blood Progenitor Cell Support in Patients with Metastatic Breast Cancer. Annals of Oncology, 8, 957-962. http://dx.doi.org/10.1023/A:1008259518263

[19] Liu, L., Qu, Q., Jiao, W., Zhang, Y., Li, X., Ding, C. and Wu, D. (2015) Increasing Aclarubicin Dose in Low-Dose 
Cytarabine and Aclarubicin in Combination with Granulocyte Colony-Stimulating Factor (CAG Regimen) Is Efficacious as Salvage Chemotherapy for Relapsed/Refractory Mixed-Phenotype Acute Leukemia. Leukemia Research, 39, 805-811. http://dx.doi.org/10.1016/j.leukres.2015.04.006

[20] Untch, M., Fasching, P.A., Konecny, G.E., et al. (2011) PREPARE Trial: A Randomized Phase III Trial Comparing Preoperative, Dose-Dense, Dose-Intensified Chemotherapy with Epirubicin, Paclitaxel and CMF versus a StandardDosed Epirubicin/Cyclophosphamide Followed by Paclitaxel \pm Darbepoetin Alfa in Primary Breast Cancer-Results at the Time of Surgery. Annals of Oncology, 22, 1988-1989. http://dx.doi.org/10.1093/annonc/mdq709

[21] Oberlin, O., Rey, A., Sanchez de Toledo, J., Martelli, H., Jenney, M.E., Scopinaro, M., Bergeron, C., Merks, J.H., Bouvet, N., Ellershaw, C., Kelsey, A., Spooner, D. and Stevens, M.C. (2012) Randomized Comparison of Intensified Six-Drug versus Standard Three-Drug Chemotherapy for High-Risk Nonmetastatic Rhabdomyosarcoma and Other Chemotherapy-Sensitive Childhood Soft Tissue Sarcomas: Long-Term Results from the International Society of Pediatric Oncology MMT95 Study. Journal of Clinical Oncology, 30, 2457-2465. http://dx.doi.org/10.1200/JCO.2011.40.3287

[22] Kim, D.S., Kang, K.W., Lee, S.R., Park, Y., Sung, H.J., Kim, S.J., Choi, C.W. and Kim, B.S. (2015) Comparison of Consolidation Strategies in Acute Myeloid Leukemia: High-Dose Cytarabine Alone versus Intermediate-Dose Cytarabine Combined with Anthracyclines. Annals of Hematology, 94, 1485-1492. http://dx.doi.org/10.1007/s00277-015-2389-9

[23] Caroli-Bosc, F.X., Van Laethem, J.L., Michel, P., Gay, F., Hendlisz, A., Forget, F. and Bleiberg, H. (2001) A Weekly 24-h Infusion of High-Dose 5-Fluorouracil (5-FU)+Leucovorin and Bi-Weekly Cisplatin (CDDP) Was Active and Well Tolerated in Patients with Non-Colon Digestive Carcinomas. European Journal of Cancer, 37, 1828-1832. http://dx.doi.org/10.1016/S0959-8049(01)00180-0

[24] Ramsingh, G., Westervelt, P., McBride, A., et al. Phase I Study of Cladribine, Cytarabine (Ara-C), Granulocyte Colony Stimulating Factor (G-CSF) (CLAG Regimen) and Simultaneous Escalating Doses of Imatinib Mesylate (Gleevec) in Relapsed/Refractory AML. Leukemia \& Lymphoma, 36, 589-593.

[25] Dartigeas, C., Van Den Neste, E., Berthou, C., Maisonneuve, H., Leprêtre, S., Dilhuydy, M.S., Béné, M.C., Nguyen-Khac, F., Letestu, R., Cymbalista, F., De Guibert, S., Aurran, T., Laribi, K., Vilque, J.P., Tournilhac, O., Delmer, A., Feugier, P., Cazin, B., Michallet, A.S., Lévy, V., Troussard, X., Delepine, R., Tavernier, E., Colombat, P. and Leblond, V. (2015) Evaluating Abbreviated Induction with Fludarabine, Cyclophosphamide, and Dose-Dense Rituximab in Elderly Patients with Chronic Lymphocytic Leukemia. Leukemia \& Lymphoma, 1-19.

[26] Hofmann, M.A., Gabriel, V., Milling, A., Kiecker, F., Sterry, W. and Trefzer, U. (2007) High-Dose Platinum Combination Therapy in Pretreated Patients with Disseminated Melanoma. Chemotherapy, 53, 422-428. http://dx.doi.org/10.1159/000110007

[27] Ostrow, S., Egorin, M., Aisner, J., Bachur, N. and Wiernik, P.H. (1980) High-Dose Cis-Diamminedichloro-Platinum Therapy in Patients with Advanced Breast Cancer: Pharmacokinetics, Toxicity, and Therapeutic Efficacy. Cancer Clinical Trials, 3, 23-27.

[28] Hastings, C., Gaynon, P.S., Nachman, J.B., Sather, H.N., Lu, X., Devidas, M. and Seibel, N.L. Increased Post-Induction Intensification Improves Outcome in Children and Adolescents with a Markedly Elevated White Blood Cell Count ( $\geq 200 \times 10(9) /$ l) with T Cell Acute Lymphoblastic Leukaemia but Not B Cell Disease. A Report from the Children’s Oncology Group.

[29] Mulherin, B.P., Brames, M.J. and Einhorn, L.H. (2015) Long-Term Survival with Paclitaxel and Gemcitabine for Germ Cell Tumors after Progression Following High-Dose Chemotherapy with Tandem Transplant. American Journal of Clinical Oncology, 38, 373-6SA.

[30] Beausoleil, M., Ernst, D.S., Stitt, L. and Winquist, E. (2012) Consolidative High-Dose Chemotherapy after Conventional-Dose Chemotherapy as First Salvage Treatment for Male Patients with Metastatic Germ Cell Tumours. Canadian Urological Association Journal, 6, 111-114. http://dx.doi.org/10.5489/cuaj.11233

[31] Suleiman, Y., Siddiqui, B.K., Brames, M.J., et al. (2013) Salvage Therapy with High-Dose Chemotherapy and Peripheral Blood Stem Cell Transplant in Patients with Primary Mediastinal Nonseminomatous Germ Cell Tumors. Biology of Blood and Marrow Transplantation, 19, 161-163. http://dx.doi.org/10.1016/j.bbmt.2012.08.002

[32] Henderson, I.C., Hayes, D.F. and Gelman, R. (1988) Dose-Response in the Treatment of Breast Cancer: A Critical Review. Journal of Clinical Oncology, 6, 1501-1515.

[33] Hortobagyi, G.N. (1999) High-Dose Chemotherapy for Primary Breast Cancer: Facts versus Anecdotes. Journal of Clinical Oncology, 17, 25-29.

[34] Lalle, M., De Rosa, L., Perillo, A., Scambia, G., D’Aprile, M. and Antimi, M. (2004) High-Dose Chemotherapy for Metastatic Breast Cancer. Clinical Therapeutics, 155, 305.

[35] Tjan-Heijnen, V.C., Postmus, P.E. and Wagener, D.J. (1997) Dose Intensification of Chemotherapy and the Role of Granulocyte Colony Stimulating Factor and Granulocyte Macrophage Colony Stimulating Factor in Small Cell Lung 
Cancer. Anticancer Drugs, 8, 549-564. http://dx.doi.org/10.1097/00001813-199707000-00002

[36] Liu, D., Zheng, X., Chen, J., Liu, G., Xu, Y., Shen, Y., Xie, L., Zhao, W., Jiang, G. and Fan, M. (2015) Induction Chemotherapy with Cetuximab, Vinorelbine-Cisplatin Followed by Thoracic Radiotherapy and Concurrent Cetuximab, Vinorelbine-Cisplatin in Patients with Unresectable Stage III Non-Small Cell Lung Cancer. Lung Cancer, 89, 249-254. http://dx.doi.org/10.1016/j.lungcan.2015.06.004

[37] Meropol, N.J., Miller, L.L., Korn, E.L., Braitman, L.E., MacDermott, M.L. and Schuchter, L.M. (1992) Severe Myelosuppression Resulting from Concurrent Administration of Granulocyte Colony-Stimulating Factor and Cytotoxic Chemotherapy. Journal of the National Cancer Institute, 84, 1201-1203. http://dx.doi.org/10.1093/jnci/84.15.1201

[38] Rowinsky, E., Sartorius, S. and Grochow, L. (1992) Phase I and Pharmacologic Study of Topotecan, an Inhibitor of Topoisomerase I, with Granulocyte Colony-Stimulating Factor (G-CSF): Toxicologic Differences between Concurrent and Post-Treatment G-CSF Administration. Proc Asco, 11, 284.

[39] Rowinsky, E.K., Grochow, L.B. and Sartorius, S.E. (1996) Phase I and Pharmacologic Study of High Doses of the Topoisomerase I Inhibitor Topotecan with Granulocyte Colony-Stimulating Factor in Patients with Solid Tumors. Journal of Clinical Oncology, 14, 1224-1235.

[40] Weiss, A.J. and Lackman, R.D. (1994) Dose Intensification by the Simultaneous Use of rh-G-CSF and Anti-Cancer Chemotherapy. International Journal of Oncology, 6, 329-332.

[41] Weiss, A.J. and Lackman, R.D. (2002) A Comparison of Human G-Csf and Human Gm-Csf Given Concurrently with Anti-Cancer Chemotherapy. Oncology Reports, 9, 945-950. http://dx.doi.org/10.3892/or.9.5.945

[42] Lokich, J.J. (2006) Same Day Pegfilgrastim and CHOP Chemotherapy for Non-Hodgkin Lymphoma. American Journal of Clinical Oncology, 29, 361-363. http://dx.doi.org/10.1097/01.coc.0000217816.16236.22

[43] Lokich, J. (1999) Single-Dose Granulocyte Colony-Stimulating Factor Concomitant with Multifractionated Dose Chemotherapy: A Strategy for Maintaining Dose Intensity. Cancer Investigation, 17, 547-550. http://dx.doi.org/10.3109/07357909909032865

[44] Weiss, A.J., Stoloff, I.L., Simoes, A.C. and Lackman, R.D. (2014) The Relation between the Initial Type of Schedule Used to Administer Doxorubicin and Long-Term Doxorubicin Cardiotoxicity. Journal of Cancer Therapy, 5, 11451152. http://dx.doi.org/10.4236/jct.2014.512117

[45] Weiss, A.J., Sabol, J. and Lackman, R.D. (1999) Concurrent Administration of Vinorelbine with Recombinant Human Granulocyte Colony-Stimulating Factor: An Effective Method of Increasing Dose Intensity. American Journal of Clinical Oncology, 22, 38-41. http://dx.doi.org/10.1097/00000421-199902000-00010

[46] Smith, T.J., Bohlke, K., Lyman, G.H., et al. (2015) Recommendations for the Use of WBC Growth Factors: American Society of Clinical Oncology Clinical Practice Guideline Update. Journal of Clinical Oncology, Published Online.

[47] Bunn Jr., P.A., Crowley, J., Kelly, K., Hazuka, M.B., Beasley, K., Upchurch, C., Livingston, R., Weiss, G.R., Hicks, W.J. and Gandara, D.R. (1995) Chemoradiotherapy with or without Granulocyte-Macrophage Colony-Stimulating Factor in the Treatment of Limited-Stage Small-Cell Lung Cancer: A Prospective Phase III Randomized Study of the Southwest Oncology Group. Journal of Clinical Oncology, 13, 1632-1641. Erratum in: Journal of Clinical Oncology, 13, 286.

[48] Lipson, E.J., Sharfman, W.H., Chen, S., McMiller, T.L., Pritchard, T.S., Salas, J.T., Sartorius-Mergenthaler, S., Freed, I., Ravi, S., Wang, H., Luber, B., Sproul, J.D., Taube, J.M., Pardoll, D.M. and Topalian, S.L. (2015) Safety and Immunologic Correlates of Melanoma GVAX, a GM-CSF Secreting Allogeneic Melanoma Cell Vaccine Administered in the Adjuvant Setting. Journal of Translational Medicine, 13, 214. http://dx.doi.org/10.1186/s12967-015-0572-3

[49] Edmonson, H.J., Long, J.H. and Kvols, K.L. (1997) Can Molgramostim Enhance the Antitumor Effects of Cytotoxic Drugs in Patients with Advanced Sarcomas? Annals of Oncology, 8, 637-641. http://dx.doi.org/10.1023/A:1008292010062

[50] Huang, C.C., Kuo, K.K., Cheng, T.C., Chuang, C.H., Kao, C.H., Hsieh, Y.C., Cheng, K.H., Wang, J.Y., Cheng, C.M., Chen, C.S. and Cheng, T.L. (2015) Development of Membrane-Bound GM-CSF and IL-18 as an Effective Tumor Vaccine. PLoS ONE, 10, e0133470. http://dx.doi.org/10.1371/journal.pone.0133470

[51] van Broekhoven, C.L., Parish, C.R., Demangel, C., Britton, W.J. and Altin, J.G. (2004) Targeting Dendritic Cells with Antigen-Containing Liposomes: A Highly Effective Procedure for Induction of Antitumor Immunity and for Tumor Immunotherapy. Cancer Research, 64, 4357-4365. http://dx.doi.org/10.1158/0008-5472.CAN-04-0138

[52] Gupta, S., Termini, J.M., Rivas, Y., Otero, M., Raffa, F.N., Bhat, V., Farooq, A. and Stone, G.W. (2015) A MultiTrimeric Fusion of CD40L and gp100 Tumor Antigen Activates Dendritic Cells and Enhances Survival in a B16-F10 Melanoma DNA Vaccine Model. Vaccine, in Press. http://dx.doi.org/10.1016/j.vaccine.2015.07.081

[53] Li, H., Wang, C., Yu, J., Cao, S., Wei, F., Zhang, W., Han, Y. and Ren, X.B. (2009) Dendritic Cell-Activated Cytokine-Induced Killer Cells Enhance the Anti-Tumor Effect of Chemotherapy on Non-Small Cell Lung Cancer in Patients after Surgery. Cytotherapy, 11, 1076-1083. http://dx.doi.org/10.3109/14653240903121252 
[54] Arndt, C.A., Koshkina, N.V., Inwards, C.Y., Hawkins, D.S., Krailo, M.D., Villaluna, D., Anderson, P.M., Goorin, A.M., Blakely, M.L., Bernstein, M., Bell, S.A., Ray, K., Grendahl, D.C., Marina, N. and Kleinerman, E.S. (2010) Inhaled Granulocyte-Macrophage Colony Stimulating Factor for First Pulmonary Recurrence of Osteosarcoma: Effects on Disease-Free Survival and Immunomodulation. A Report from the Children's Oncology Group. Clinical Cancer Research, 16, 4024-4030. http://dx.doi.org/10.1158/1078-0432.CCR-10-0662

[55] Palombi, M., Niscola, P., Tendas, A., Trawinska, M.M., Scaramucci, L., Giovannini, M., Fratoni, S., Perrotti, A. and de Fabritiis, P. (2013) Simultaneous Occurrence of Large B-Cell Non-Hodgkin Lymphoma and Acute Myeloid Leukaemia in an Elderly Patient: Complete Remissions of Both Diseases by Rituximab-Bendamustine Regimen Combined to Hypomethylating Therapy. Journal of Chemotherapy, 25, 247-249. http://dx.doi.org/10.1179/1973947813Y.0000000076

[56] Cantarow, A. and Zagerman, A.J. (1964) Fluorouracil Inhibition of Teserone-Stimulated Growth of Seminal Vesicles. Proceedings of the Society for Experimental Biology and Medicine, 115, 1052-1054. http://dx.doi.org/10.3181/00379727-115-29113

[57] Paschkis, K.E., Bartuska, D., Zagerman, J., Goddard, J.W. and Cantarow, A. (1959) Effect of 5-Fluorouracil on Noncancerous Tissue Growth. Cancer Research, 19, 1196-1203.

[58] Zagerman, J. and Cantarow, A. (1962) 5-Fluorouracil Inhibition of Testosterone-Stimulated Growth of Seminal Vesicles. Cancer Chemotherapy Reports, 22, 37-38.

[59] ISMP Canada (2007) Fluorouracil Incident Root Cause Analysis. April 30, 2007 (Formatted for Posting on the Alberta Cancer Board Website on May 23, 2007). ISMP Canada. Fluorouracil Incident RCA: Follow-Up. ISMP Canada Safety Bulletin, 7, 1-4.

www.cancerboard.ab.ca/NR/rdonlyres/2FB61BC4-70CA-4E58-BDE1-1E54797BA47D/0/FluorouracilIncidentMay200 $\underline{7 . p d f}$

[60] Biffi, R., de Braud, F., Orsi, F., Pozzi, S., Mauri, S., Goldhirsch, A., Nolè, F. and Andreoni, B. (1998) Totally Implantable Central Venous Access Ports for Long-Term Chemotherapy. A Prospective Study Analyzing Complications and Costs of 333 Devices with a Minimum Follow-Up of 180 Days. Annals of Oncology, 9, 767-773. http://dx.doi.org/10.1023/A:1008392423469 